\title{
Angiogenic biomarkers in pregnancy: defining maternal and fetal health.
}

Running head: Biomarkers in pregnancy and future health

Lene Gjersøe Rasmussen, MD, ${ }^{1,2}$; Jacob Alexander Lykke, $\mathrm{MD}, \mathrm{PhD}^{2,3,4}$; Anne Cathrine Staff, $\mathrm{MD}, \mathrm{PhD}^{1,5}$

${ }^{1}$ Department of Obstetrics and Gynec ology, Oslo University Hospital, Oslo, Norway

${ }^{2}$ Faculty of Medicine, University of Copenhagen, Copenhagen, Denmark

${ }^{3}$ Department of Obstetrics and Gynecology, Hvidovre University Hospital, Copenhagen, Denmark

${ }^{4}$ Departement of Obstetrics, Rigshospitalet Copenhagen University Hospital, Copenhagen, Denmark

${ }^{5}$ Faculty of Medicine, University of Oslo, Oslo, Norway

Corresponding author:

Dr Lene Gjersøe Rasmussen

Address: Akershus University Hospital, Postboks 1000, 1478 Lørenskog

Email: lene.gjersoe $@$,ahus.no

Telephone: 004791774452

[Skriv tekst] 


\begin{abstract}
Abs tract
We review diagnostic and predictive roles of the angiogenic proteins placental growth factor, soluble fms-like tyrosine kinase 1 and soluble endoglin in preeclampsia, and their association with future cardiovascular disease, diabetes and breast cancer. Specific patterns of these proteins represent preeclamptic prediction markers and combined with maternal and clinical characteristics, the predictive values increase. Women experiencing preeclampsia have increased risks of developing cardiovascular diseases and diabetes, and a decreased risk of breast cancer. High placental growth factor concentrations have in elderly patients been shown to predict cardiovascular events. Diabetes is also a risk factor for future cardiovascular disease. Diabetic vascular complications are associated with increased soluble endoglin concentrations, and vascular endothelial growth factor concentrations are correlated to HbAlc and fasting glucose. Thus dysregulation in angiogenic proteins may link preeclampsia and cardiovascular diseases, targeting women who could in future benefit from prophylactic programs topossibly prevent, delay or reduce cardiovascular disease.
\end{abstract}

\title{
$\underline{\text { Key Words : }}$
}

Hypertension, Pregnancy, Preeclampsia, Maternal morbidity, Maternal mortality, Molecular biology, Women's Health, High-risk pregnancies, Angiogenic factors.

\section{Key Message:}

Dysregulated circulating angiogenic proteins are associated with preeclampsia and placental dysfunction. These proteins may also be dysregulated in diabetes, cardiovascular disease and breast cancer. We suggest potential pathophysiological links, and through these some possibilities for prevention directed towards young women at increased risk for these diseases. 


\section{Abbreviations:}

FGR: fetal growth restriction

CVD: cardiovascular disease

DM: diabetes mellitus

SGA: small-for-gestational age

GDM: gestational diabetes

PlGF: placental growth factor

sFlt1: soluble fms-like tyrosine kinase-1

sEng: soluble endoglin

VEGF: vascular endothelial growth factor

\section{Introduction}

Preeclampsia and fetal growth restriction (FGR) are pregnancy complications associated with an increased risk for short- and long-term morbidity and mortality for both the mother and her offspring, such as adding to the risk for developing future cardiovascular disease (CVD) and diabetes mellitus (DM) $(1 ; 2)$. Simultaneously, women have a decreased risk of breast cancer development after preeclampsia (3-5), although this is not confirmed in all epidemiological studies (6).

The patophysiology of the preeclampsia syndrome is still elusive and not completely understood. The disease is, however, clinically and pragmatically usually defined as hypertension and proteinuria developing after 20 weeks of gestation (7). Preeclampsia has often been subdivided into "placental" and "maternal" forms, stating unique patterns of pathogenesis and health issues both in the short and long term $(8 ; 9)$. 
"Placental preeclampsia" is thought to arise from incomplete remodeling of the uteroplacental spiral arteries, presumably caused by dysregulated immunological interactions between fetal extravillous trophoblasts and maternal immune cells (10) leading to dysfunctional uteroplacental flow and excessive oxidative and endoplasmatic reticulum stress in the placenta (11). The dysfunctional placenta releases factors into the circulation causing a systemic inflammatory response (12) and generalized endothelial dysfunction mediating the clinical maternal signs of hypertension and proteinuria (13). These placenta-generated factors include angiogenic proteins, and we have previously discussed their application in pregnancy as biomarkers of a dysfunctional placenta (14).

"Maternal preeclampsia" is considered to develop in women with a normal placentation. Predisposing factors associated with augmented inflammation such as obesity, DM and autoimmune diseases make the mother more susceptible to developing endothelial dysfunction, hypertension and proteinuria as a response to factors released from a normally functioning placenta (1). "Placental preeclampsia", with incompletely remodeled uteroplacental spiral arteries, is thought to more often associated with early-onset disease and FGR, whereas the "maternal type" of preeclampsia, without apparent remodeling problems, is more often associated with late-onset disease, although a mix of both these not well-defined preeclampsia forms is probably the more common condition (14).

The risk factors for developing preeclampsia seem also to segregate into the two subgroups of preeclampsia. Previous preeclampsia and nulliparity deviate towards the "placental" type, whereas obesity, high maternal age and diabetes, - much the same risk factors as for CVD, predispose to the "maternal type" (15). These clinical factors have, however, a limited predictive value in evaluating the risk for preeclampsia (16). Likewise, pathological blood flow patterns in the uterine artery assessed by Doppler ultrasound, have limited value in the general screening for low- 
risk pregnancies. Uterine artery blood flow as well as umbilical cord flow patterns are, however, widely used in the clinical setting to follow up high-risk patients with present or previous pregnancy complications associated with placental dysfunction (16).

No cause-specific treatment for clinically established preeclampsia is available at present. Delivery of the baby and thereby the placenta leads to amelioration of the clinical symptoms, paralleling a rapid decrease in the maternal circulating level of anti-angiogenic factors. Following a preeclamptic pregnancy, both the woman and her offspring are, however, at elevated risk for developing CVD (2;17-22). The American Heart Association introduced in 2011 preeclampsia and FGR as risk factors for CVD (23), but there is today no agreed follow-up protocol for CVD relating to pregnancy complications, partly due to an inability to identify the women at highest risk within these populations.

An improved subclassification of preeclampsia and FGR based on unique patterns of angiogenic biomarkers rather than on crude syndromic signs may provide useful in triaging women for follow-up, both during pregnancy and postpartum (14). This might prove valuable for better timing of delivery in a pregnancy at risk for adverse maternal and offspring outcomes, and could be followed by potentially improved health outcomes for the mother and offspring (14).

Several distinct circulating maternal angiogenic proteins appear to be present at abnormal levels in pregnant women with overt preeclampsia or growth restricted fetuses; furthermore, the relative and absolute concentrations of these proteins are altered prior to the clinical signs of these pregnancy complications $(16 ; 24)$. This review summarizes the findings for the most assessed antiand pro-angiogenic circulating proteins in relation to pregnancy complications and their potential predictive roles hereto. In addition, a potential role of these circulating biomarkers in relation to future adult CVD, DM and breast cancer is discussed. 


\section{Material and methods}

For the present review, a non-systematic PubMed search on was performed. Search words included 'Preeclampsia/Intrauterine Growth Restriction/FGR/Small-for-Gestational Age/CVD/DM/Breast Cancer" in a combination with "Angiogenic factors/P1GF/sFlt/sEng/Prediction". Additional eligible studies were sought by hand search of reference lists from primary articles and reviews. We published a comprehensive review of potential preeclamptic plasma biomarkers in 2010 (16), with a completed article search up to September 2009.

The present review has in addition included published articles as a result of a second PubMed search from September 2009 to November 2012, using same search words as above, primarily clinical cohort studies, case-control studies and clinical trials. We selected relevant published articles in English, based upon the senior authors' expertise of the field (A.C.S. and J.A.L.). This review is based on a report in 2013 by the first author, and important published articles on the topic from 2013 and 2014 were thereafter included under the same criteria as above. This review does not present a graded evaluation of the statistically significant associations presented between the angiogenic biomarkers and disease.

\section{Results}

\section{Preeclampsia and future health risks}

Several studies have shown increased risk of long-term cardiovascular complications such as coronary heart disease, tromboembolism, hypertension, stroke and CVD-associated death following 
a history of preeclampsia or the delivery of a small-for-gestational age (SGA) infant (10;17-19;2531). The risk is highest among women who develop both preeclampsia and FGR (28), for those with early-onset preeclampsia $(17 ; 18 ; 25 ; 31)$, repeated preeclampsia $(28)$ or severe preeclampsia (18). The relative risk after preeclampsia for developing CVD varies from 1.3 to 3.3, with a higher risk range of 2.7-8.1 in more severe preeclampsia (32), implying a "dose-response" relation between severity of preeclampsia and future CVD. FGR implies failure to realize a genetically determined growth potential and many FGR fetuses, but not all, will also be SGA. Not all SGA fetuses are FGR, they are just constitutionally small. The fetal growth terminology is controversial and inconsistent among obstetricians; however, the most widely used definition of SGA is fetal weight below the $10^{\text {th }}$ percentile (33).

Cardiovascular risk factors present before a hypertensive pregnancy could be important determinants of subsequent long-term cardiovascular risk after a preeclamptic pregnancy, but this does not exclude that the pregnancy by itself, and a pregnancy complication with poor placental function like the "placental" type of preeclampsia in particular $(8 ; 9)$, could also contribute to the augmented risk for later cardiovascular disease.

DM and preeclampsia share many pathophysiological features, such as inflammation, oxidative stress, insulin resistance and endothelial dysfunction (34;35). Both pre-gestational and gestational diabetes (GDM) are associated with an increased risk of developing preeclampsia (3638). ). Lykke et al. have demonstrated that a history of preeclampsia or gestational hypertension (39), as well as of FGR (40), places women at increased risk of DM later in life, in line with previous publications demonstrating increased risk of type II DM after preeclampsia (41), even in patients without co-existing GDM (42). Insulin resistance is a feature of normal pregnancy which is exaggerated in preeclampsia and even more so in GDM, and it may represent a link between these pregnancy complications and future DM and CVD (43;44). 
In contrast to an augmented risk of diseases such as CVD and DM following preeclampsia, women with a history of preeclampsia or gestational hypertension have a reduced breast cancer risk compared to women who have had only uncomplicated pregnancies $(45 ; 46)$. An even larger reduction is seen with elevated mean arterial pressures (47) and systolic blood pressures from midto late pregnancy, but below the diagnostic levels for preeclampsia (48). This inverse correlation between breast cancer and a history of preeclampsia is, however, not consistent (49). The mechanisms are at present unknown, but might be related to tumor vascularization and growth, and possibly to remote effects of dysregulated local or circulating angiogenic factors during pregnancy.

\section{Angiogenic factors and preeclampsia}

Preeclampsia is characterized by a maternal circulating anti-angiogenic profile, with elevated anti-angiogenic proteins, and decreased pro-angiogenic proteins (reviewed in (16)). This pattern is also seen prior to clinical signs of preeclampsia, and in animal models, these proteins participate in processes that induce preeclampsia-like disorders (50-53).

In normal pregnancies, the pro-angiogenic protein placental growth factor (P1GF) peaks at 30 weeks (54) and decreases towards term (55;56). It is involved in angiogenesis and vasculogenesis, which are important processes in embryogenesis (57) and placentation. In preeclampsia, circulating P1GF is decreased (58-62), especially in cases of early-onset preeclampsia $(59 ; 60 ; 62)$, although there are some discrepant findings $(61)$. When it comes to predicting preeclampsia, some studies have demonstrated that low concentrations of PlGF predict the disease already from late first trimester (16;63-70). Other studies did not find any predictive value early in pregnancy $(16 ; 56 ; 59 ; 71)$, or only for early-onset preeclampsia (64). The predictive power of a low maternal PIGF blood concentration seems in general poorer for predicting late- than early- onset 
preeclampsia, and performs less well for preeclampsia without SGA compared to preeclampsia complicated by SGA (66).

Most studies have demonstrated low P1GF as a preeclampsia predictor from the second trimester onwards $(16 ; 56 ; 63 ; 67 ; 72-77)$, especially if preeclampsia was complicated by SGA $(56 ; 60 ; 71 ; 72)$, as well as in early-onset $(56 ; 67)$ and severe preeclampsia $(59 ; 65)$. The same has been seen for the third trimester (74-76), especially (and in some studies exclusively (59)) in severe preeclampsia (78). Other studies have demonstrated that a low increase in PlGF from the first to second trimester gives a stronger association to an augmented risk than low PlGF levels, again especially for the prediction of early-onset preeclampsia $(67 ; 69 ; 72)$. A recently published study has shown that in women presenting with suspected preeclampsia before 35 weeks' gestation, low PlGF had a higher sensitivity and negative predictive value for preeclampsia within 14 days (79).

As opposed to PlGF, the maternal concentrations of the "anti-angiogenic protein" soluble fms-like tyrosine kinase-1 (sFlt1) remain stable during the first two trimesters of a normal pregnancy, and thereafter increase towards term $(56 ; 80)$. The action of sFlt1 and its interaction with the "pro-angiogenic proteins" vascular endothelial growth factor (VEGF) and P1GF during pregnancy is complex (14). It is believed that sFlt1 acts as a "decoy protein" in pregnancy, reducing free concentrations of VEGF and PlGF, thereby reducing the vasodilation effect on the endothelium, thus at the same time inducing vasoconstriction and contributing to the development of hypertension and proteinuria (58). An increased concentration of sFlt1 in the maternal circulation has been shown in preeclamptic patients (9), both in second and third trimester $(52 ; 60-62 ; 81-84)$. The associations are, similarly as for P1GF, stronger in early-onset $(60 ; 61 ; 81)$ and severe preeclampsia (52), however, not all studies agree hereto $(62 ; 85)$. Elevated sFlt1 concentrations in pregnancy have also been associated with smaller head and chest circumferences and with 
birthweight (86), as well as being positively correlated to mean arterial pressure and proteinuria $(58 ; 84)$, although there are some discrepant conclusions $(62)$.

As for predicting preeclampsia, low sFlt1 concentrations in the first trimester appear to predict early-onset preeclampsia in some studies $(67 ; 72)$, and a high sFlt1 increase from the first to the second trimester may entail an augmented risk of preeclampsia (72). Results from the latter cohort recently showed that low sFlt1 in the first trimester could predict early-onset preeclampsia independently of SGA, and also late-onset preeclampsia together with SGA (69). Other studies have not shown a predictive value for sFlt1 in the first trimester $(56 ; 67 ; 68 ; 87)$.

For the second and third trimester, most studies show that elevated maternal sFt1 concentrations predict preeclampsia development $(16 ; 56 ; 59 ; 62 ; 64 ; 69 ; 73-76 ; 87 ; 88)$, with a higher predictive power for early- than for late-onset preeclampsia $(16 ; 56 ; 88)$, however, some studies have concluded otherwise $(16 ; 63 ; 67)$. Furthermore, elevated sFlt1 has been suggested to be a better predictor of severe preeclampsia $(78 ; 88)$, or preeclampsia complicated by SGA (56). A study by Powers et al. suggested a dichotomized preeclampsia population. One subpopulation had elevated maternal sFlt before gestational week 35, representing the preeclampsia group with the highest blood pressures, the earliest gestational age at delivery and the most preterm births (59). This was in comparison to the second group of preeclamptic patients with an sFlt1 increase not seen until after week 35, lower blood pressures, less preterm deliveries and the highest gestational age at delivery. It seems that for late-onset preeclampsia, a significant increase in maternal circulating sFlt1 is only present close to the time of the diagnosis of the disease $(16 ; 56)$. The preeclampsia prediction generally improves if SGA is diagnosed in combination with preeclampsia (69).

Using several biomarkers simultaneously seems to improve preeclampsia subgrouping, both in a predictive fashion and as markers of a correct clinical diagnosis. An elevated sFlt1/P1GF ratio in pregnancy improved the prognostic value for preeclampsia as compared to single marker, 
$(16 ; 60 ; 89)$, correlating to adverse pregnancy outcomes (90), especially early-onset preeclampsia (91). As regards existing preeclampsia, the sFlt1/P1GF ratio is also elevated $(16 ; 61 ; 84)$, especially in the second trimester, i.e. for women with early-onset preeclampsia. Studies of the relation between these biomarkers in preeclampsia have suggested that the reduction in circulating maternal PlGF concentration can be detected prior to the sFlt1elevations, favoring PlGF as an early predictive marker of preeclampsia (92). Other studies conclude that PlGF is a more sensitive and precise predictor of preeclampsia and FGR than any other biomarker investigated previously (9395).

Another maternal circulating "anti-angiogenic protein", soluble endoglin (sEng), has also been demonstrated to be elevated in clinically established preeclampsia $(16 ; 51 ; 61 ; 62 ; 81-84 ; 96)$. It increases with severity of the disease $(51 ; 62)$, being highest in early-onset in disease $(61 ; 62)$. Endoglin (Eng) is a glycoprotein expressed on endothelial cells and on placental syncytiotrophoblasts, involved in transcriptional responses in the vasculature. Its soluble form, sEng, is proposed to act in concert with sFlt1 in pregnancy (89). Its circulating concentrations increase by two- and three-fold through a normal pregnancy, with regard to respectively preterm and term measurements, as compared to non-pregnant states (51). The predictive value of elevated sEng in the first trimester has, however, not been shown to be a consistent finding. Most studies have not shown a predictive value for preeclampsia $(67 ; 68 ; 87)$. Some studies including women late in first or early in second trimester $(63 ; 97)$, have suggested that sEng is elevated in women destined to develop preeclampsia, especially early-onset (97). In the second trimester the findings coincide better, and increased sEng seems to predict preeclampsia $(74 ; 78 ; 98)$, especially the early-onset and severe forms, similarly to the low PIGF and elevated sFlt1 values $(16 ; 63 ; 67 ; 74 ; 76 ; 87-89 ; 98)$. From several studies it has been suggested that a combination of maternal circulating biomarkers and clinical signs may improve the predictive values for preeclampsia compared to biomarkers alone 
$(16 ; 78)$. A superior model is presented to be the combination of mean arterial pressure with circulating sEng-values, with the highest prediction for early-onset preeclampsia (99). Similar results have been found by combining circulating sEng with maternal factors such as race, smoking, parity, weight, age, and with biophysical factors such as mean arterial pressure (100). Another study including PIGF has shown that a combination of clinical data, maternal PlGF and $\beta-\mathrm{hCG}$ concentrations measured in the first trimester can predict up to $75 \%$ of early-onset preeclamptic cases (101), although the combination with uterine artery Doppler and maternal PAPP-A concentrations increased the detection to $95 \%$, with a false positive rate of $10 \%$, suggesting another possible model in the screening for early-onset preeclampsia (102).

\section{Angiogenic factors in relation to small-for-gestational age and fetal growth restriction}

FGR has also been associated with a dysregulated maternal angiogenic profile (16). It has been shown that circulating maternal PIGF is decreased in pregnancies complicated by SGA (71) or FGR (103), also in non-preeclamptic patients. Not all studies have found significant low PLGF concentrations in FGR, even with co-existing preeclampsia (60). Similarly, increased maternal sFlt1 (62) and sEng concentrations have been found in pregnancies complicated by SGA $(62 ; 81)$. Not all studies have shown significant low P1GF concentrations in FGR, even with co-existing preeclampsia (60), but pregnancy biomarker studies are in general difficult to compare, as they differ widely in study design (particularly in gestational age inclusion for blood sampling) and population selection.

As for preeclampsia, low maternal PIGF concentrations in the first trimester $(16 ; 66 ; 67 ; 104)$ and elevated maternal sEng in the second trimester $(67 ; 70 ; 104)$ have been shown to predict SGA pregnancies. Maternal sFlt1 concentrations appear to be increased in non-preeclamptic pregnancies 
later complicated by FGR $(16 ; 105 ; 106)$, and recent studies have demonstrated a high sFlt1 increase from the first to the second trimester for predicting SGA development both in preeclamptic and non-preeclamptic patients $(69 ; 104)$. These findings are discrepant, as some studies show no predictive value for SGA following an elevated sFlt1 (76), and even a lower risk of SGA development $(16 ; 107)$.

\section{Angiogenic factors in relation to cardiovascular disease}

It has been proposed that women with acute atherosis of the uteroplacental spiral arteries, a feature of many pregnancies complicated by preeclampsia, could be at excessive risk for premature atherosclerosis and CVD development (10). These acute atherosis lesions are histological changes resembling early stages of histological atherosclerosis (108), and we have suggested that these lesions could represent an accelerated form of early atherosclerosis developed during the short time of pregnancy (1).

Another similarity between atherosclerosis and acute atherosis is the inflammatory component (108). PlGF is shown to be up-regulated in atherosclerotic lesions of patients with acute coronary syndrome, where it is believed to act as an inflammatory instigator of atherosclerotic plaque instability (109), and elevated circulating P1GF could indicate a risk for higher mortality and disease events in patients with coronary heart disease. Also, in these elderly individuals, circulating PIGF levels were positively correlated with levels of the inflammation marker CRP $(109 ; 110)$. It is suggested that the source of the elevated PlGF in the circulation of these patients is the inflamed endothelium. There is in contrast a low circulating concentration of PIGF during and prior to preeclampsia development, probably secondary to placental dysfunction and the binding of free and vascular-active PIGF as well as VEGF by the elevated amount of placenta-freed sFlt1 (52). 
Angiogenic factors in relation to diabetes mellitus

Angiogenic factors have also been investigated in order to improve the understanding of the pathogenesis and vascular complications in DM. It has been shown that elevated circulating sEng is correlated to microangiopathy, hypertension, increased disease duration, besides a family history of diabetes type 2 (111). Circulating VEGF is positively correlated to Hbalc and fasting glucose (112). It is important to underline that the latter pattern is the opposite of what is observed in preeclampsia, where it is plausible that the effect of placenta dysfunction overrides the vascular dysfunction for the circulating biomarkers that are measured in pregnancy. The common denominator is the inflamed endothelium, which in the case of preeclampsia is secondary to the placenta-mediated generalized (and vascular) inflammation (12). The complex patterns of pathogenesis in the two situations could then determine the outcome for the woman.

\section{Angiogenic factors and cancer}

The mechanisms mediating breast cancer protection after a case of gestational hypertension are unknown. We have speculated that the anti-angiogenic state implying negative growth conditions for tumor growth and metastasis plays a role in the association between a dysfunctional placenta and future reduced malignant tumor development (113). The circulating anti-angiogenic sFlt/VEGF ratio in a woman with breast cancer is inversely associated with tumor size, and it is significantly lower in breast cancer patients than controls (114). Augmented concentrations of circulating PlGF in a woman with breast cancer have been suggested to be a positive predictor of breast cancer recurrence, metastasis and patient mortality, and to be associated with its angiogenic properties (115). However, there is currently no documentation of any relation between dysregulated angiogenic responses during pregnancy and later breast cancer development, although a possible correlation cannot be excluded. 


\section{Discussion}

The circulating maternal concentrations of the angiogenic biomarkers in pregnancy are a net result of many complex processes (1). The study of their association to preeclampsia, cardiovascular disease, diabetes mellitus and breast cancer may generate new insights to the pathophysiology of these diseases and suggest mechanisms for their pathophysiological interaction. A high release of anti-angiogenic factors such as sFlt1 from a dysfunctional placenta is proposed to have a negative impact on the maternal endothelium by neutralizing beneficial VEGF and P1GF in the circulation (52), but the direct relation of this to future vascular disease is unknown. Due to their relation to preeclampsia, and also to the epidemiological association between preeclampsia, DM and CVD, we speculate that these biomarkers may be useful in risk-selection of women for postpartum intervention trials aimed at reducing the risk for, or the severity of, these later-life diseases.

The demonstrated role of PlGF in enhancing blood flow and contractile function of ischemic myocardium underlines its role in vascular homeostasis, and provides room for a hypothesis of an indirect interplay between preeclampsia and CVD (116). If PlGF improves myocardial function, and its levels decrease during preeclampisa, it is possible that the low P1GF state of preeclampsia can contribute as a factor increasing the risk of CVD through long-term effects on cardiac function. sEng, released in excess from a dysfunctional placenta, may have negative effects on vascular tone (51), possibly also adding to the factors that may mediate a relation between preeclampsia, CVD and DM. A genetical link between CVD and preeclampsia is also under investigation, and recent research by our group has demonstrated a G-protein phenotype, which plays a role in blood pressure regulation, which also affects the risk for and progression of preeclampsia (117). 
As for breast cancer, an anti-angiogenic state opposes tumor development (118). We propose that a woman's general angiogenic response disposition, whether in pregnancy or if challenged by breast tumor growth, might represent a link between the anti-angiogenic state in pregnancy and a later beneficial low tumor growth situation in the same woman.

At present, longitudinal studies after a preeclamptic pregnancy point in different directions regarding long-term angiogenic dysregulation. Some studies show no difference in the concentrations of circulating PlGF and sFlt1, measured both one (119) and ten (120) years postpartum between women with previous preeclampsia and control individuals. The same is seen for sEng one year post-partum (119). One study showed that circulating sFlt1 levels are raised 18 months after preeclampsia (121). We also found higher median circulating sFlt1 in women with previous preeclampsia complicated by SGA in our own long-term follow-up study (5-8 years after preeclampsia), together with evidence of maternal and child endothelial dysfunction (122). In several studies increased arterial stiffness after preeclampsia has been shown $(119 ; 123 ; 124)$.

As circulating PIGF has opposite patterns in CVD and preeclampsia, with augmented levels in the former and very low levels in the latter, there is no intuitive logical link between these two syndromes with abnormal P1GF situations. Circulating P1GF is elevated in older persons with a high risk of a future CVD event, where circulating PlGF stems from excessive vascular inflammation. In contrast, low P1GF in pregnancy (probably mostly due to binding of free P1GF to excessive sFlt1 secondary to a dysfunctional placenta) appears predictive of preeclampsia and fetal growth restriction. At present we do not know whether a dysregulated angiogenic factor situation in pregnancy is just a marker of the future health risk for the women, possibly reflecting a common genetic risk for preeclampsia and future cardiovascular disease. The other alternative is that dysregulated angiogenic factors in pregnancy could also mediate future health problems, for 
example by directly or indirectly affecting vascular health. The first alternative does not exclude the latter.

An interesting link between CVD and preeclampsia is that both have foam cell deposition in arteries, as preeclampsia often is complicated by uteroplacental acute atherosis (10). We are at present studying whether there is a link between these vascular inflammatory changes in CVD and preeclampsia and are using a decidual vacuum suction method that is optimal for collecting relevant uteroplacental tissue to study inflammatory lesions of these uteroplacental arteries (125).

As women with a history of hypertensive disorders in pregnancy have an increased risk for developing future diabetes mellitus $(36-38 ; 42))$, a prevention program and follow-up would be desirable, but this is not the clinical practice world-wide. GDM is a strong risk factor for future diabetes, and women with GDM are today in many countries recommended to undergo postpartum DM screening (43). According to the annual report of the Norwegian Medical Birth Register (126), more women experience gestational hypertension and preeclampsia than GDM. We therefore believe that the group of women who have experienced gestational hypertension or preeclampsia are important candidates for DM (127) as well as for CVD follow-up programs, in order to prevent or enable early diagnosis and treatment of these diseases.

Current available tests for the circulating angiogenic factors sFlt1, sEng and PlGF have too low sensitivity and specificity to be used singularly as a screening tool for preeclampsia in low-risk pregnancies, although the use of PIGF in women with suspected preeclampsia after week 35 is promising. No cost-benefit analyses have hitherto been published comparing these biomarkers or their combinations, but among the single biomarkers, PIGF seems today to be the better predictor for preeclampsia (128).

Cnossen argues that when it comes to the questions of specificity and sensitivity in screening for preeclampsia, high sensitivity is preferable, if one has to choose (129). Preeclampsia 
is a disease that can result in maternal and fetal death, and low sensitivity is therefore absolutely unfavorable. On the other hand, low specificity will lead to unnecessary use of health resources and cause unnecessary concern and burden for healthy pregnant women. Future studies must bear in mind that the ultimate goal of the research on preeclampsia-related biomarkers is not to predict and reduce the incidence of preeclampsia, but to improve maternal and child health, both in the short and in the long run.

Currently, there are few effective primary or secondary prophylaxis options for preeclampsia. A limited effect of acetylsalicylic acid is known; and women at elevated risk of developing preeclampsia are recommended daily acetylsalicylic acid from around week 12 of pregnancy $(130 ; 131)$. Several other clinical intervention studies have attempted to prevent preeclampsia development by testing effects of vitamins, fish oil, diets, calcium and exercise (132138), but they have not been successful in reducing the preeclampsia-risk across populations. A good predictive biomarker could potentially be useful to select and monitor high-risk patients for future prophylactic trials. Maternal angiogenic factors measured early in pregnancy or at diagnosis of preeclampsia could have a potential use in this setting. In developing countries, with limited blood assessment accessibility, a urine dip-stix test would be preferable, and probably also costeffective compared to blood testing. Urine based biomarkers for PE have, however, up to the present time not been proven to be of use (16).

Further validation of the clinical use of placenta-associated biomarkers, such as the angiogenic factors, is necessary. Cost-benefit analyses are needed before routine clinical implementation of maternal angiogenic factors. Also, longitudinal studies across pregnancy cohorts are needed to assess whether dysregulated maternal angiogenic factors measured in pregnancy can be securely associated with future risk of cardiovascular disease, diabetes mellitus and possibly breast cancer (53). The future hope is that a combination of biomarkers reflecting both the placental 
(such as PlGF) and maternal pathophysiology of preeclampsia (such as preexisting risk factors in the mother), as well as dysregulated cardiovascular-derived circulating biomarkers (139) may improve diagnostic accuracy and clinical management of preeclampsia and link to future health risks (1). It is time to improve the subgrouping of preeclampsia, perhaps using angiogenic placentaderived biomarkers such as PIGF (14). Despite great advances both clinically and research-wise in industrialized countries over the last decades, our pathophysiological understanding of preeclampsia is still relatively limited. This limitation may have consequences for the low predictive value of angiogenic factors for late-onset preeclampsia. In late-onset preeclampsia dysregulated placentation is not viewed as an essential pathophysiological event. That could possibly explain why this subgroup of preeclamptic women is less well predicted by dysregulated circulating placenta-derived biomarkers, and is in line with our new hypothesis that circulating angiogenic biomarkers in pregnancy are better considered as markers of a syncytiotrophoblast stress-response rather than of preeclampsia or fetal growth restriction (140).

If we can document a relation (even if there would be no mechanistic associations) between dysregulated angiogenic factors in pregnancy (most likely due to placental dysfunction) and an augmented risk for future CVD, targeted intervention studies for women at highest risk could be undertaken in order to prevent, postpone or reduce the severity of CVD. The several decades (22) that may lie between a pregnancy with a dysfunctional placenta and the first clinical signs of CVD represent a large "window of opportunity" for intervention programs in women at highest risk, with potentially reduced health cost for the woman, her family and society and for enhancing quality of life. 


\section{Conflicts of interest:}

Lene Gjersøe Rasmussen: none. Jacob Alexander Lykke has received speaker's fee for plenary lectures on thrombophilia and pregnancy outcomes from Leo Pharmacies in November 2012 and November 2014. Anne Cathrine Staff has received speaker's fee for research group laboratory activities for a plenary biomarker lecture at an IFPA meeting in 2012 from Roche Diagnostics, Japan.

[Skriv tekst] 


\section{References}

(1) Staff AC, Dechend R, Redman CW. Review: Preeclampsia, acute atherosis of the spiral arteries and future cardiovascular disease: Two new hypotheses. Placenta 2013 Mar;34Suppl:S73-S78.

(2) Jonsdottir LS, Arngrimsson R, Geirsson RT, Sigvaldason H, Sigfusson N. Death rates from ischemic heart disease in women with a history of hypertension in pregnancy. Acta Obstet Gynecol Scand 1995 Nov;74(10):772-6.

(3) Innes KE, Byers TE. First pregnancy characteristics and subsequent breast cancer risk among young women. Int J Cancer 2004 Nov 1;112(2):306-11.

(4) Aagaard-Tillery KM, Stoddard GJ, Holmgren C, Lacoursiere DY, Fraser A, Mineau GP, et al. Preeclampsia and subsequent risk of cancer in Utah. Am J Obstet Gynecol 2006 Sep;195(3):691-9.

(5) Opdahl S, Romundstad PR, Alsaker MD, Vatten LJ. Hypertensive diseases in pregnancy and breast cancer risk. Br J Cancer 2012 Jun 26;107(1):176-82.

(6) Brasky TM, Li Y, Jaworowicz DJ, Jr., Potischman N, Ambrosone CB, Hutson AD, et al. Pregnancy-related characteristics and breast cancer risk. Cancer Causes Control 2013 Sep;24(9):1675-85.

(7) ACOG practice bulletin. Diagnosis and management of preeclampsia and eclampsia. Number 33, January 2002. American College of Obstetricians and Gynecologists. Int J Gynaecol Obstet 2002 Apr;77(1):67-75.

(8) Lazdam M, de la Horra A, Diesch J, Kenworthy Y, Davis E, Lewandowski AJ, et al. Unique blood pressure characteristics in mother and offspring after early onset preeclampsia. Hypertension 2012 Nov;60(5):1338-45.

(9) van Rijn BB, Nijdam ME, Bruinse HW, Roest M, Uiterwaal CS, Grobbee DE, et al. Cardiovascular disease risk factors in women with a history of early-onset preeclampsia. Obstet Gynecol 2013 May;121(5):1040-8.

(10) Staff AC, Dechend R, Pijnenborg R. Learning from the placenta: acute atherosis and vascular remodeling in preeclampsia-novel aspects for atherosclerosis and future cardiovascular health. Hypertension 2010 Dec;56(6):1026-34.

(11) Burton GJ, Yung HW, Cindrova-Davies T, Charnock-Jones DS. Placental endoplasmic reticulum stress and oxidative stress in the pathophysiology of unexplained intrauterine growth restriction and early onset preeclampsia. Placenta 2009 Mar;30 Suppl A:S43-S48.

(12) Redman CW, Sacks GP, Sargent IL. Preeclampsia: an excessive maternal inflammatory response to pregnancy. Am J Obstet Gynecol 1999 Feb;180(2 Pt 1):499-506. 
(13) Redman CW, Sargent IL. Latest advances in understanding preeclampsia. Science 2005 Jun 10;308(5728):1592-4.

(14) Staff AC, Benton SJ, von DP, Roberts JM, Taylor RN, Powers RW, et al. Redefining preeclampsia using placenta-derived biomarkers. Hypertension 2013 May;61(5):932-42.

(15) Duckitt K, Harrington D. Risk factors for pre-eclampsia at antenatal booking: systematic review of controlled studies. BMJ 2005 Mar 12;330(7491):565.

(16) Staff A. Circulating predictive biomarkers in preeclampsia. Pregnancy Hypertension: An International Journal of Women's Cardiovascular Health 2010;1:28-42.

(17) Bellamy L, Casas JP, Hingorani AD, Williams DJ. Pre-eclampsia and risk of cardiovascular disease and cancer in later life: systematic review and meta-analysis. BMJ 2007 Nov 10;335(7627):974.

(18) Wikstrom AK, Haglund B, Olovsson M, Lindeberg SN. The risk of maternal ischaemic heart disease after gestational hypertensive disease. BJOG 2005 Nov;112(11):1486-91.

(19) Irgens HU, Reisaeter L, Irgens LM, Lie RT. Long term mortality of mothers and fathers after pre-eclampsia: population based cohort study. BMJ 2001 Nov 24;323(7323):1213-7.

(20) Tenhola S, Rahiala E, Martikainen A, Halonen P, Voutilainen R. Blood pressure, serum lipids, fasting insulin, and adrenal hormones in 12-year-old children born with maternal preeclampsia. J Clin Endocrinol Metab 2003 Mar;88(3):1217-22.

(21) Vatten LJ, Romundstad PR, Holmen TL, Hsieh CC, Trichopoulos D, Stuver SO. Intrauterine exposure to preeclampsia and adolescent blood pressure, body size, and age at menarche in female offspring. Obstet Gynecol 2003 Mar;101(3):529-33.

(22) Arnadottir GA, Geirsson RT, Arngrimsson R, Jonsdottir LS, Olafsson O. Cardiovascular death in women who had hypertension in pregnancy: a case-control study. BJOG 2005 Mar;112(3):286-92.

(23) Mosca L, Benjamin EJ, Berra K, Bezanson JL, Dolor RJ, Lloyd-Jones DM, et al. Effectiveness-based guidelines for the prevention of cardiovascular disease in women-2011 update: a guideline from the american heart association. Circulation $2011 \mathrm{Mar}$ 22;123(11):1243-62.

(24) Kleinrouweler CE, Wiegerinck MM, Ris-Stalpers C, Bossuyt PM, van der Post JA, von DP, et al. Accuracy of circulating placental growth factor, vascular endothelial growth factor, soluble fms-like tyrosine kinase 1 and soluble endoglin in the prediction of preeclampsia: a systematic review and meta-analysis. BJOG 2012 Jun;119(7):778-87.

(25) Melchiorre K, Sutherland GR, Liberati M, Thilaganathan B. Preeclampsia is associated with persistent postpartum cardiovascular impairment. Hypertension 2011 Oct;58(4):70915.

(26) Williams D. Pregnancy: a stress test for life. Curr Opin Obstet Gynecol 2003 Dec;15(6):465-71. 
(27) Smith GC, Pell JP, Walsh D. Pregnancy complications and maternal risk of ischaemic heart disease: a retrospective cohort study of 129,290 births. Lancet 2001 Jun 23;357(9273):2002-6.

(28) Lykke JA, Langhoff-Roos J, Sibai BM, Funai EF, Triche EW, Paidas MJ. Hypertensive pregnancy disorders and subsequent cardiovascular morbidity and type 2 diabetes mellitus in the mother. Hypertension 2009 Jun;53(6):944-51.

(29) Fraser A, Nelson SM, Macdonald-Wallis C, Cherry L, Butler E, Sattar N, et al. Associations of pregnancy complications with calculated cardiovascular disease risk and cardiovascular risk factors in middle age: the Avon Longitudinal Study of Parents and Children. Circulation 2012 Mar 20;125(11):1367-80.

(30) Smith GN, Pudwell J, Walker M, Wen SW. Ten-year, thirty-year, and lifetime cardiovascular disease risk estimates following a pregnancy complicated by preeclampsia. J Obstet Gynaecol Can 2012 Sep;34(9):830-5.

(31) Lykke JA, Langhoff-Roos J, Lockwood CJ, Triche EW, Paidas MJ. Mortality of mothers from cardiovascular and non-cardiovascular causes following pregnancy complications in first delivery. Paediatr Perinat Epidemiol 2010 Jul 1;24(4):323-30.

(32) Newstead J, von DP, Magee LA. Preeclampsia and future cardiovascular risk. Expert Rev Cardiovasc Ther 2007 Mar;5(2):283-94.

(33) Unterscheider J, Daly S, Geary MP, Kennelly MM, McAuliffe FM, O'Donoghue K, et al. Definition and management of fetal growth restriction: a survey of contemporary attitudes. Eur J Obstet Gynecol Reprod Biol 2014 Mar;174:41-5.

(34) Kaaja R. Insulin resistance syndrome in preeclampsia. Semin Reprod Endocrinol 1998;16(1):41-6.

(35) Schram MT, Chaturvedi N, Schalkwijk C, Giorgino F, Ebeling P, Fuller JH, et al. Vascular risk factors and markers of endothelial function as determinants of inflammatory markers in type 1 diabetes: the EURODIAB Prospective Complications Study. Diabetes Care 2003 Jul;26(7):2165-73.

(36) Garner PR, D'Alton ME, Dudley DK, Huard P, Hardie M. Preeclampsia in diabetic pregnancies. Am J Obstet Gynecol 1990 Aug;163(2):505-8.

(37) Barden A, Singh R, Walters BN, Ritchie J, Roberman B, Beilin LJ. Factors predisposing to pre-eclampsia in women with gestational diabetes. J Hypertens 2004 Dec;22(12):23718.

(38) Roach VJ, Hin LY, Tam WH, Ng KB, Rogers MS. The incidence of pregnancy-induced hypertension among patients with carbohydrate intolerance. Hypertens Pregnancy 2000;19(2):183-9.

(39) Smith GN, Pudwell J, Walker M, Wen SW. Ten-year, thirty-year, and lifetime cardiovascular disease risk estimates following a pregnancy complicated by preeclampsia. J Obstet Gynaecol Can 2012 Sep;34(9):830-5. 
(40) Lykke JA, Paidas MJ, Triche EW, Langhoff-Roos J. Fetal growth and later maternal death, cardiovascular disease and diabetes. Acta Obstet Gynecol Scand 2012 Apr;91(4):503-10.

(41) Williams D. Long-term complications of preeclampsia. Semin Nephrol 2011 Jan;31(1):111-22.

(42) Feghali M, Miodovnik M. Diabetes: hypertension during pregnancy and future diabetes mellitus. Nat Rev Endocrinol 2013 Aug;9(8):446-7.

(43) ACOG Practice Bulletin. Clinical management guidelines for obstetrician-gynecologists. Number 30, September 2001 (replaces Technical Bulletin Number 200, December 1994). Gestational diabetes. Obstet Gynecol 2001 Sep;98(3):525-38.

(44) Seely EW, Solomon CG. Insulin resistance and its potential role in pregnancy-induced hypertension. J Clin Endocrinol Metab 2003 Jun;88(6):2393-8.

(45) Troisi R, Weiss HA, Hoover RN, Potischman N, Swanson CA, Brogan DR, et al. Pregnancy characteristics and maternal risk of breast cancer. Epidemiology 1998 Nov;9(6):641-7.

(46) Vatten LJ, Romundstad PR, Trichopoulos D, Skjaerven R. Pre-eclampsia in pregnancy and subsequent risk for breast cancer. Br J Cancer 2002 Oct 21;87(9):971-3.

(47) Richardson BE, Peck JD, Wormuth JK. Mean arterial pressure, pregnancy-induced hypertension, and preeclampsia: evaluation as independent risk factors and as surrogates for high maternal serum alpha-fetoprotein in estimating breast cancer risk. Cancer Epidemiol Biomarkers Prev 2000 Dec;9(12):1349-55.

(48) Cohn BA, Cirillo PM, Christianson RE, van den Berg BJ, Siiteri PK. Placental characteristics and reduced risk of maternal breast cancer. J Natl Cancer Inst 2001 Aug 1;93(15):1133-40.

(49) Nechuta S, Paneth N, Velie EM. Pregnancy characteristics and maternal breast cancer risk: a review of the epidemiologic literature. Cancer Causes Control 2010 Jul;21(7):967-89.

(50) Karumanchi SA, Stillman IE. In vivo rat model of preeclampsia. Methods Mol Med 2006;122:393-9.

(51) Venkatesha S, Toporsian M, Lam C, Hanai J, Mammoto T, Kim YM, et al. Soluble endoglin contributes to the pathogenesis of preeclampsia. Nat Med 2006 Jun;12(6):642-9.

(52) Maynard SE, Min JY, Merchan J, Lim KH, Li J, Mondal S, et al. Excess placental soluble fms-like tyrosine kinase 1 (sFlt1) may contribute to endothelial dysfunction, hypertension, and proteinuria in preeclampsia. J Clin Invest 2003 Mar;111(5):649-58.

(53) Isha Agarwal SAK. Preeclampsia and the anti-angiogenic state. Pregnancy Hypertension: An International Journal of Women's Cardiovascular Health 2011 Jan 1;1(1):17-21. 
(54) Saffer S, Olson G, Buggess KA, Beyerlein R, Eubank C, Sibai BM, et al. Determination of placental growth factor (PLGF) levels in health pregnant women without signs or symptoms of preeclampsia. Pregnancy Hypertension: An International Journal of Women's Cardiovascular Health 2013 Apr;3(2):124-32.

(55) Levine RJ, Thadhani R, Qian C, Lam C, Lim KH, Yu KF, et al. Urinary placental growth factor and risk of preeclampsia. JAMA 2005 Jan 5;293(1):77-85.

(56) Levine RJ, Maynard SE, Qian C, Lim KH, England LJ, Yu KF, et al. Circulating angiogenic factors and the risk of preeclampsia. N Engl J Med 2004 Feb 12;350(7):67283.

(57) Khalil A, Muttukrishna S, Harrington K, Jauniaux E. Effect of antihypertensive therapy with alpha methyldopa on levels of angiogenic factors in pregnancies with hypertensive disorders. PLoS ONE 2008;3(7):e2766.

(58) Staff AC, Braekke K, Harsem NK, Lyberg T, Holthe MR. Circulating concentrations of sFlt1 (soluble fms-like tyrosine kinase 1) in fetal and maternal serum during preeclampsia. Eur J Obstet Gynecol Reprod Biol 2005 Sep 1;122(1):33-9.

(59) Powers RW, Roberts JM, Plymire DA, Pucci D, Datwyler SA, Laird DM, et al. Low placental growth factor across pregnancy identifies a subset of women with preterm preeclampsia: type 1 versus type 2 preeclampsia? Hypertension 2012 Jul;60(1):239-46.

(60) Sunderji S, Gaziano E, Wothe D, Rogers LC, Sibai B, Karumanchi SA, et al. Automated assays for sVEGF R1 and PIGF as an aid in the diagnosis of preterm preeclampsia: a prospective clinical study. Am J Obstet Gynecol 2010 Jan;202(1):40-7.

(61) Masuyama H, Segawa T, Sumida Y, Masumoto A, Inoue S, Akahori Y, et al. Different profiles of circulating angiogenic factors and adipocytokines between early- and late-onset pre-eclampsia. BJOG 2010 Feb;117(3):314-20.

(62) Kim YN, Lee DS, Jeong DH, Sung MS, Kim KT. The relationship of the level of circulating antiangiogenic factors to the clinical manifestations of preeclampsia. Prenat Diagn 2009 May;29(5):464-70.

(63) Kusanovic JP, Romero R, Chaiworapongsa T, Erez O, Mittal P, Vaisbuch E, et al. A prospective cohort study of the value of maternal plasma concentrations of angiogenic and anti-angiogenic factors in early pregnancy and midtrimester in the identification of patients destined to develop preeclampsia. J Matern Fetal Neonatal Med 2009 Nov;22(11):1021-38.

(64) Vatten LJ, Eskild A, Nilsen TI, Jeansson S, Jenum PA, Staff AC. Changes in circulating level of angiogenic factors from the first to second trimester as predictors of preeclampsia. Am J Obstet Gynecol 2007 Mar;196(3):239-6.

(65) Audibert F, Boucoiran I, An N, Aleksandrov N, Delvin E, Bujold E, et al. Screening for preeclampsia using first-trimester serum markers and uterine artery Doppler in nulliparous women. Am J Obstet Gynecol 2010 Oct;203(4):383-8. 
(66) Cowans NJ, Stamatopoulou A, Matwejew E, von Kaisenberg CS, Spencer K. Firsttrimester placental growth factor as a marker for hypertensive disorders and SGA. Prenat Diagn 2010 Jun;30(6):565-70.

(67) Erez O, Romero R, Espinoza J, Fu W, Todem D, Kusanovic JP, et al. The change in concentrations of angiogenic and anti-angiogenic factors in maternal plasma between the first and second trimesters in risk assessment for the subsequent development of preeclampsia and small-for-gestational age. J Matern Fetal Neonatal Med 2008 May;21(5):279-87.

(68) Myatt L, Clifton RG, Roberts JM, Spong CY, Hauth JC, Varner MW, et al. First-trimester prediction of preeclampsia in nulliparous women at low risk. Obstet Gynecol 2012 Jun;119(6):1234-42.

(69) Vatten LJ, Asvold BO, Eskild A. Angiogenic factors in maternal circulation and preeclampsia with or without fetal growth restriction. Acta Obstet Gynecol Scand 2012 Dec;91(12):1388-94.

(70) Romero R, Nien JK, Espinoza J, Todem D, Fu W, Chung H, et al. A longitudinal study of angiogenic (placental growth factor) and anti-angiogenic (soluble endoglin and soluble vascular endothelial growth factor receptor-1) factors in normal pregnancy and patients destined to develop preeclampsia and deliver a small for gestational age neonate. J Matern Fetal Neonatal Med 2008 Jan;21(1):9-23.

(71) Taylor RN, Grimwood J, Taylor RS, McMaster MT, Fisher SJ, North RA. Longitudina 1 serum concentrations of placental growth factor: evidence for abnormal placental angiogenesis in pathologic pregnancies. Am J Obstet Gynecol 2003 Jan;188(1):177-82.

(72) Vatten LJ, Eskild A, Nilsen TI, Jeansson S, Jenum PA, Staff AC. Changes in circulating level of angiogenic factors from the first to second trimester as predictors of preeclampsia. Am J Obstet Gynecol 2007 Mar;196(3):239-6.

(73) Shokry M, Bedaiwy MA, Fathalla MM, Alsemary A, Elwakil S, Murphy A. Maternal serum placental growth factor and soluble fms-like tyrosine kinase 1 as early predictors of preeclampsia. Acta Obstet Gynecol Scand 2010;89(1):143-6.

(74) Mijal RS, Holzman CB, Rana S, Karumanchi SA, Wang J, Sikorskii A. Mid-pregnancy levels of angiogenic markers as indicators of pathways to preterm delivery. J Matern Fetal Neonatal Med 2012 Jul;25(7):1135-41.

(75) Leanos-Miranda A, Campos-Galicia I, Isordia-Salas I, Rivera-Leanos R, Romero-Arauz $\mathrm{JF}$, Ayala-Mendez JA, et al. Changes in circulating concentrations of soluble fms-like tyrosine kinase-1 and placental growth factor measured by automated electrochemiluminescence immunoassays methods are predictors of preeclampsia. J Hypertens 2012 Nov;30(11):2173-81.

(76) Romero R, Nien JK, Espinoza J, Todem D, Fu W, Chung H, et al. A longitudinal study of angiogenic (placental growth factor) and anti-angiogenic (soluble endoglin and soluble vascular endothelial growth factor receptor-1) factors in normal pregnancy and patients 
destined to develop preeclampsia and deliver a small for gestational age neonate. J Matern Fetal Neonatal Med 2008 Jan;21(1):9-23.

(77) Tjoa ML, van Vugt JM, Mulders MA, Schutgens RB, Oudejans CB, van Wijk IJ. Plasma placenta growth factor levels in midtrimester pregnancies. Obstet Gynecol 2001 Oct;98(4):600-7.

(78) Moore AG, Young H, Keller JM, Ojo LR, Yan J, Simas TA, et al. Angiogenic biomarkers for prediction of maternal and neonatal complications in suspected preeclampsia. J Matern Fetal Neonatal Med 2012 Aug 22.

(79) Chappell LC, Duckworth S, Seed PT, Griffin M, Myers J, Mackillop L, et al. Diagnostic accuracy of placental growth factor in women with suspected preeclampsia: a prospective multicenter study. Circulation 2013 Nov 5;128(19):2121-31.

(80) Buhimschi CS, Baumbusch MA, Dulay AT, Lee S, Wehrum M, Zhao G, et al. The role of urinary soluble endoglin in the diagnosis of pre-eclampsia: comparison with soluble fmslike tyrosine kinase 1 to placental growth factor ratio. BJOG 2010 Feb;117(3):321-30.

(81) Haggerty CL, Seifert ME, Tang G, Olsen J, Bass DC, Karumanchi SA, et al. Second trimester anti-angiogenic proteins and preeclampsia. Pregnancy Hypertens 2012 Apr 1;2(2):158-63.

(82) Reddy A, Suri S, Sargent IL, Redman CW, Muttukrishna S. Maternal circulating levels of activin A, inhibin A, sFlt-1 and endoglin at parturition in normal pregnancy and preeclampsia. PLoS ONE 2009;4(2):e4453.

(83) Faupel-Badger JM, Wang Y, Staff AC, Karumanchi SA, Stanczyk FZ, Pollak M, et al. Maternal and cord steroid sex hormones, angiogenic factors, and insulin-like growth factor axis in African-American preeclamptic and uncomplicated pregnancies. Cancer Causes Control 2012 May;23(5):779-84.

(84) Aggarwal PK, Chandel N, Jain V, Jha V. The relationship between circulating endothelin1, soluble fms-like tyrosine kinase-1 and soluble endoglin in preeclampsia. J Hum Hypertens 2012 Apr;26(4):236-41.

(85) Sezer SD, Kucuk M, Yenisey C, Yuksel H, Odabasi AR, Turkmen MK, et al. Comparison of angiogenic and anti-angiogenic factors in maternal and umbilical cord blood in earlyand late-onset pre-eclampsia. Gynecol Endocrinol 2012 Aug;28(8):628-32.

(86) Kulkarni AV, Mehendale SS, Yadav HR, Kilari AS, Taralekar VS, Joshi SR. Circulating angiogenic factors and their association with birth outcomes in preeclampsia. Hypertens Res 2010 Jun;33(6):561-7.

(87) Rana S, Karumanchi SA, Levine RJ, Venkatesha S, Rauh-Hain JA, Tamez H, et al. Sequential changes in antiangiogenic factors in early pregnancy and risk of developing preeclampsia. Hypertension 2007 Jul;50(1):137-42. 
(88) Stepan H, Geipel A, Schwarz F, Kramer T, Wessel N, Faber R. Circulatory soluble endoglin and its predictive value for preeclampsia in second-trimester pregnancies with abnormal uterine perfusion. Am J Obstet Gynecol 2008 Feb;198(2):175-6.

(89) Levine RJ, Lam C, Qian C, Yu KF, Maynard SE, Sachs BP, et al. Soluble endoglin and other circulating antiangiogenic factors in preeclampsia. N Engl J Med 2006 Sep 7;355(10):992-1005.

(90) Rana S, Powe CE, Salahuddin S, Verlohren S, PerschelFH, Levine RJ, et al. Angiogenic factors and the risk of adverse outcomes in women with suspected preeclampsia. Circulation 2012 Feb 21;125(7):911-9.

(91) Rana S, Powe CE, Salahuddin S, Verlohren S, PerschelFH, Levine RJ, et al. Angiogenic factors and the risk of adverse outcomes in women with suspected preeclampsia. Circulation 2012 Feb 21;125(7):911-9.

(92) Thadhani R, Mutter WP, Wolf M, Levine RJ, Taylor RN, Sukhatme VP, et al. First trimester placental growth factor and soluble fms-like tyrosine kinase 1 and risk for preeclampsia. J Clin Endocrinol Metab 2004 Feb;89(2):770-5.

(93) Akolekar R, Syngelaki A, Poon L, Wright D, Nicolaides KH. Competing risks model in early screening for preeclampsia by biophysical and biochemical markers. Fetal Diagn Ther 2013;33(1):8-15.

(94) Chen G, Zhang L, Jin X, Zhou Y, Niu J, Chen J, et al. Effects of Angiogenic Factors, Antagonists, and Podocyte Injury on Development of Proteinuria in Preeclampsia. Reprod Sci 2013 May;20(5):579-88.

(95) Boucoiran I, Suarthana E, Rey E, Delvin E, Fraser WB, Audibert F. Repeated Measures of Placental Growth Factor, Placental Protein 13, and A Disintegrin and Metalloprotease 12 at First and Second Trimesters for Preeclampsia Screening. Am J Perinatol 2013 Sep;30(8):681-8.

(96) Hertig A, Fort J, Lefevre G, Chabbert-Buffet N, Uzan M, Rondeau E, et al. Soluble endoglin in preeclamptic patients with or without HELLP syndrome. Am J Obstet Gynecol 2010 Jun;202(6):594.

(97) Foidart JM, Munaut C, Chantraine F, Akolekar R, Nicolaides KH. Maternal plasma soluble endoglin at 11-13 weeks' gestation in pre-eclampsia. Ultrasound Obstet Gynecol 2010 Jun;35(6):680-7.

(98) Chaiworapongsa T, Romero R, Savasan ZA, Kusanovic JP, Ogge G, Soto E, et al. Maternal plasma concentrations of angiogenic/anti-angiogenic factors are of prognostic value in patients presenting to the obstetrical triage area with the suspicion of preeclampsia. J Matern Fetal Neonatal Med 2011 Oct;24(10):1187-207.

(99) Abdelaziz A, Maher MA, Sayyed TM, Bazeed MF, Mohamed NS. Early pregnancy screening for hypertensive disorders in women without a-priori high risk. Ultrasound Obstet Gynecol 2012 Oct;40(4):398-405. 
(100) Akolekar R, Syngelaki A, Sarquis R, Zvanca M, Nicolaides KH. Prediction of early, intermediate and late pre-eclampsia from maternal factors, biophysical and biochemical markers at 11-13 weeks. Prenat Diagn 2011 Jan;31(1):66-74.

(101) Di LG, Ceccarello M, Cecotti V, Ronfani L, Monasta L, Vecchi BL, et al. First trimester maternal serum PIGF, free beta-hCG, PAPP-A, PP-13, uterine artery Doppler and maternal history for the prediction of preeclampsia. Placenta 2012 Jun;33(6):495-501.

(102) Akolekar R, Syngelaki A, Poon L, Wright D, Nicolaides KH. Competing Risks Model in Early Screening for Preeclampsia by Biophysical and Biochemical Markers. Fetal Diagn Ther 2012 Aug 16.

(103) Benton SJ, Hu Y, Xie F, Kupfer K, Lee SW, Magee LA, et al. Can placental growth factor in maternal circulation identify fetuses with placental intrauterine growth restriction? Am J Obstet Gynecol 2012 Feb;206(2):163-7.

(104) Asvold BO, Vatten LJ, Romundstad PR, Jenum PA, Karumanchi SA, Eskild A. Angiogenic factors in maternal circulation and the risk of severe fetal growth restriction. Am J Epidemiol 2011 Mar 15;173(6):630-9.

(105) Stepan H, Unversucht A, Wessel N, Faber R. Predictive value of maternal angiogenic factors in second trimester pregnancies with abnormal uterine perfusion. Hypertension 2007 Apr;49(4):818-24.

(106) Stepan H, Geide A, Faber R. Soluble fms-like tyrosine kinase 1. N Engl J Med 2004 Nov $18 ; 351(21): 2241-2$.

(107) Smith GC, Crossley JA, Aitken DA, Jenkins N, Lyall F, Cameron AD, et al. Circulating angiogenic factors in early pregnancy and the risk of preeclampsia, intrauterine growth restriction, spontaneous preterm birth, and stillbirth. Obstet Gynecol 2007 Jun;109(6):1316-24.

(108) Staff AC, Redman CW. IFPA Award in Placentology Lecture: Preeclampsia, the decidual battleground and future maternal cardiovascular disease. Placenta 2014 Feb;35 Suppl:S26S31.

(109) Lenderink T, Heeschen C, Fichtlscherer S, Dimmeler S, Hamm CW, Zeiher AM, et al. Elevated placental growth factor levels are associated with adverse outcomes at four-year follow-up in patients with acute coronary syndromes. J Am Coll Cardiol 2006 Jan 17;47(2):307-11.

(110) Heeschen C, Dimmeler S, Fichtlscherer S, Hamm CW, Berger J, Simoons ML, et al. Prognostic value of placental growth factor in patients with acute chest pain. JAMA 2004 Jan 28;291(4):435-41.

(111) Ak G, Buyukberber S, Sevinc A, Turk HM, Ates M, Sari R, et al. The relation between plasma endothelin-1 levels and metabolic control, risk factors, treatment modalities, and diabetic microangiopathy in patients with Type 2 diabetes mellitus. J Diabetes Complications 2001 May;15(3):150-7. 
(112) Kakizawa H, Itoh M, Itoh Y, Imamura S, Ishiwata Y, Matsumoto T, et al. The relationship between glycemic control and plasma vascular endothelial growth factor and endothelin-1 concentration in diabetic patients. Metabolism 2004 May;53(5):550-5.

(113) Troisi R, Braekke K, Harsem NK, Hyer M, Hoover RN, Staff AC. Blood pressure augmentation and maternal circulating concentrations of angiogenic factors at delivery in preeclamptic and uncomplicated pregnancies. Am J Obstet Gynecol 2008 Dec;199(6):65310.

(114) Hoar FJ, Lip GY, Belgore F, Stonelake PS. Circulating levels of VEGF-A, VEGF-D and soluble VEGF-A receptor (sFIt-1) in human breast cancer. Int J Biol Markers 2004 Jul;19(3):229-35.

(115) Parr C, Watkins G, Boulton M, Cai J, Jiang WG. Placenta growth factor is over-expressed and has prognostic value in human breast cancer. Eur J Cancer 2005 Dec;41(18):2819-27.

(116) Liu X, Claus P, Wu M, Reyns G, Verhamme P, Pokreisz P, et al. Placental Growth Factor Increases Regional Myocardial Blood Flow and Contractile Function in Chronic Myocardial Ischemia. Am J Physiol Heart Circ Physiol 2013 Mar 15;304(6):H885-H894.

(117) Kvehaugen AS, Melien O, Holmen OL, Laivuori H, Oian P, Andersgaard AB, et al. Single nucleotide polymorphisms in $\mathrm{G}$ protein signaling pathway genes in preeclampsia. Hypertension 2013 Mar;61(3):655-61.

(118) Folkman J. The role of angiogenesis in tumor growth. Semin Cancer Biol 1992 Apr;3(2):65-71.

(119) Yinon Y, Kingdom JC, Odutayo A, Moineddin R, Drewlo S, Lai V, et al. Vascular dysfunction in women with a history of preeclampsia and intrauterine growth restriction: insights into future vascular risk. Circulation 2010 Nov 2;122(18):1846-53.

(120) Gaugler-Senden IP, Tamsma JT, van der Bent C, Kusters R, Steegers EA, de Groot CJ. Angiogenic factors in women ten years after severe very early onset preeclampsia. PLoS ONE 2012;7(8):e43637.

(121) Wolf M, Hubel CA, Lam C, Sampson M, Ecker JL, Ness RB, et al. Preeclampsia and future cardiovascular disease: potential role of altered angiogenesis and insulin resis tance. J Clin Endocrinol Metab 2004 Dec;89(12):6239-43.

(122) Kvehaugen AS, Dechend R, Ramstad HB, Troisi R, Fugelseth D, Staff AC. Endothelial function and circulating biomarkers are disturbed in women and children after preeclampsia. Hypertension 2011 Jul;58(1):63-9.

(123) Hausvater A, Giannone T, Sandoval YH, Doonan RJ, Antonopoulos CN, Matsoukis IL, et al. The association between preeclampsia and arterial stiffness. J Hypertens 2012 Jan;30(1):17-33.

(124) Goynumer G, Yucel N, Adali E, Tan T, Baskent E, Karadag C. Vascular risk in women with a history of severe preeclampsia. J Clin Ultrasound 2012 Jul 14. 
(125) Burton GJ, Sebire NJ, Myatt L, Tannetta D, Wang YL, Sadovsky Y, et al. Optimising sample collection for placental research. Placenta 2014 Jan;35(1):9-22.

(126) Årstabeller for Medisinsk fødselsregister 2011, Folkehelseinstituttet. www fhi no/dokumenter/2a92108f4f pdf 2013

(127) Roberts CL, Ford JB, Algert CS, Antonsen S, Chalmers J, Cnattingius S, et al. Populationbased trends in pregnancy hypertension and pre-eclampsia: an international comparative study. BMJ Open 2011 Jan 1;1(1):e000101.

(128) Chappell LC, Duckworth S, Seed PT, Griffin M, Myers J, Mackillop L, et al. Diagnostic accuracy of placental growth factor in women with suspected preeclampsia: a prospective multicenter study. Circulation 2013 Nov 5;128(19):2121-31.

(129) Cnossen JS, Ter RG, Mol BW, van der Post JA, Leeflang MM, Meads CA, et al. Are tests for predicting pre-eclampsia good enough to make screening viable? A review of reviews and critical appraisal. Acta Obstet Gynecol Scand 2009;88(7):758-65.

(130) Duley L, Henderson-Smart DJ, Meher S, King JF. Antiplatelet agents for preventing preeclampsia and its complications. Cochrane Database Syst Rev 2007;(2):CD004659.

(131) National Collaborating Centre for Women's and Children's Health (UK). Hypertension in Pregnancy: The Management of Hypertensive Disorders During Pregnancy. NICE Clinical Guidelines, No. 107. RCOG Press; 2010.

(132) Briley AL, Poston L, Shennan AH. Vitamins C and E and the prevention of preeclampsia. N Engl J Med 2006 Sep 7;355(10):1065-6.

(133) Haugen M, Brantsaeter AL, Trogstad L, Alexander J, Roth C, Magnus P, et al. Vitamin D supplementation and reduced risk of preeclampsia in nulliparous women. Epidemiology 2009 Sep;20(5):720-6.

(134) Roberts JM, Myatt L, Spong CY, Thom EA, Hauth JC, Leveno KJ, et al. Vitamins C and E to prevent complications of pregnancy-associated hypertension. N Engl J Med 2010 Apr 8;362(14):1282-91.

(135) Shennan AH, Poston L, Chappell LC, Seed PT. Prevention of pre-eclampsia. Lancet 2001 May 12;357(9267):1534.

(136) Brantsaeter AL, Haugen M, Samuelsen SO, Torjusen H, Trogstad L, Alexander J, et al. A dietary pattern characterized by high intake of vegetables, fruits, and vegetable oils is associated with reduced risk of preeclampsia in nulliparous pregnant Norwegian women. $\mathbf{J}$ Nutr 2009 Jun;139(6):1162-8.

(137) Chandiramani M, Seed P, Poston L, Shennan AH. Antiplatelet agents for prevention of pre-eclampsia. Lancet 2007 Nov 17;370(9600):1685-6.

(138) Christesen HT, Falkenberg T, Lamont RF, Jorgensen JS. The impact of vitamin D on pregnancy: A systematic review. Acta Obstet Gynecol Scand 2012 Dec;91(12):1357-67. 
(139) Sugulle M, Herse F, Hering L, Mockel M, Dechend R, Staff AC. Cardiovascular biomarker midregional proatrial natriuretic peptide during and after preeclamptic pregnancies. Hypertension 2012 Feb;59(2):395-401.

(140) Redman CW, Sargent IL, Staff AC. IFPA Senior Award Lecture: making sense of preeclampsia - two placental causes of preeclampsia? Placenta 2014 Feb;35 Suppl:S20-S25. 